\title{
A retrospective study: platinum-based induction chemotherapy combined with gemcitabine or paclitaxel for stage IIB-IIIA central non-small-cell lung cancer
}

Chao Lv', Yuanyuan Ma' ${ }^{1}$ Nan Wu' ${ }^{1}$ Shi Yan ${ }^{1}$, Qingfeng Zheng ${ }^{1}$, Yu Sun², Shaolei Li ${ }^{1}$, Jian Fang ${ }^{3}$ and Yue Yang ${ }^{1 *}$

\begin{abstract}
Background: Several encouraging phase III clinical trials have evaluated platinum-based induction chemotherapy against stage IIB-IIIA non-small-cell lung cancer (NSCLC). Chemotherapy efficacy was assessed using common regimens in this retrospective analysis.

Methods: From 2007 to 2011, the clinical records of stage IIB-IIIA NSCLC patients undergoing surgery after neoadjuvant chemotherapy were reviewed. Gathered data were tested for significance and variables impacting survival were assessed by univariate and Cox regression analyses.

Results: Overall, $84 \%$ of patients were male and $93 \%$ had central disease. Platinum-based chemotherapy protocols with gemcitabine or paclitaxel gave an overall response rate of 55\% (45/82) and 6.1\% pathological complete response (5/82). Clinical response was unassociated with regimen or histology, while more pneumonectomies were performed in the stable compared to partial response disease group ( $P=0.040)$. Postoperative mortality was $1.2 \%$ (1/82), and complications, unassociated with regimen or histology, were atelectasis (26.8\%) and supraventricular arrhythmias (13.4\%). Right-sided procedures appeared to increase the incidence of bronchopleural fistula $(P=0.073)$. The median disease-free survival time was 18 months and median overall survival time was not reached. Disease-free survival rates at one, two, and three years were $54 \%, 47 \%$, and $33 \%$, while the overall survival rate was $73 \%, 69 \%$, and 59\%, respectively. Disease-free survival predictors were radiographic response and mediastinal lymphadenopathy before chemotherapy ( $P=0.012$ and 0.002 , respectively).

Conclusions: Two cycles of platinum-based chemotherapy with gemcitabine or paclitaxel is efficacious for patients with stage IIB-IIIA central disease. Patients achieving clinical response had improved disease-free survival times, while those with mediastinal lymphadenopathy had a higher postoperative recurrence risk.
\end{abstract}

Keywords: Non-small-cell lung cancer, Induction chemotherapy, Central disease, Resection, Squamous

\section{Background}

Lung cancer in stage IIB-IIIA generally has an unfavorable prognosis, with poor five-year survival rates ranging from 19 to $25 \%$ for those using clinical stage prediction and 24 to $36 \%$ for those using pathological stage prediction, respectively [1]. Complete surgical resection has a

\footnotetext{
* Correspondence: zlyangyue@bjmu.edu.cn

'Department of Thoracic Surgery II, Key Laboratory of Carcinogenesis and Translational Research (Ministry of Education), Peking University Cancer Hospital \& Institute, Peking, China

Full list of author information is available at the end of the article
}

low survival and high recurrence rate, although effective systemic therapies, including perioperative chemotherapy, radiation and combined modality therapies, have shown potential benefits in numerous clinical trials.

Following surgery, neoadjuvant chemotherapy has the potential advantage of reducing tumor volume and eradicating micrometastatic disease, thereby improving the outcome. However, the Medical Research Council (MRC) LU22 trial in 2007, which evaluated the role of induction chemotherapy prior to surgery, failed to show evidence of a difference in overall survival (OS) between neoadjuvant chemotherapy

\section{Biomed Central}


and surgery alone. In this randomized multicenter trial, 519 patients with stages IA-IIIB lung cancer, of whom $61 \%$ had stage IA or IB disease, received either surgery alone or a combination of surgery with one of six chemotherapy regimens [2]. Three years later, the Southwest Oncology Group (SWOG) 9900 trial, aimed at evaluating the efficacy of preoperative paclitaxel and carboplatin, achieved a trend toward improved OS (Hazard Ratio $=0.79$ ) and diseasefree survival $(\mathrm{DFS})(\mathrm{HR}=0.80)$ in the induction chemotherapy arm [3]. The (Neo)Adjuvant Taxol/Carboplatin Hope (NATCH) trial included 624 patients with stage IA, IB, II, or IIIA(T3N1) NSCLC. This study finally demonstrated that no statistically significant differences in DFS were found with the addition of either preoperative or adjuvant chemotherapy to surgery [4]. However, a meta-analysis of 13 randomized control trials published in the same year concluded that neoadjuvant chemotherapy would improve the OS of operable NSCLC patients, including patients with stage III disease [5]. The recently published Chemotherapy in Early Stages Trial (ChEST), yielded a significant improvement in both DFS $(\mathrm{HR}=0.51)$ and OS $(\mathrm{HR}=0.42)$ in patients with clinical stage IIB-IIIA NSCLC using preoperative gemcitabine plus cisplatin [6].

Based on the above findings, we retrospectively reviewed all cases of clinical stage IIB-IIIA NSCLC whose treatment included a platinum-based induction therapy prior to surgery at our center, from the past five years, in order to comprehensively analyze the efficacy, potential complications and impact on survival of this treatment modality.

\section{Methods}

\section{Patients and methods}

We retrospectively reviewed the clinical records of patients who underwent surgery for NSCLC following neoadjuvant chemotherapy at Peking University Cancer Hospital from January 2007 to December 2011. All the patients had been diagnosed with NSCLC by means of biopsy, and a pretreatment evaluation was performed which included a chest computed tomography (CT) scan, a magnetic resonance imaging (MRI) scan of the brain and a bone scan in addition to an ultrasound examination of the abdomen and supraclavicular lymph nodes. Positron emission tomography - computed tomography (PET/CT) scans were not routinely used. By searching our database, patients were selected for this study based on the following features: (1) presence of central disease with T2bN1, T3 or T4 N0 to N1, or locally advanced disease with T1 to T3 N2; (2) had undergone at least two cycles of platinum-based chemotherapy preoperatively; (3) had no advanced disease such as N3 or M1; and (4) had not received radiotherapy as induction therapy. Clinical variables were recorded in detail including age, sex, histological type, clinical TNM stage, disease location, chemotherapy regimen, clinical response, type of resection, postoperative complications, final pathological TNM stage, disease recurrence and survival. Specifically, long-term survival and follow-up data were obtained from either electronic medical records or the medical statistics office. If survival or death could not be confirmed, a telephone interview was carried out in order to obtain the information.

\section{Treatment}

All patients received platinum-based chemotherapy in one department of the hospital. Treatment consisted of gemcitabine $\left(1,250 \mathrm{mg} / \mathrm{m}^{2}\right.$ on days one and eight) followed by cisplatin $\left(75 \mathrm{mg} / \mathrm{m}^{2}\right.$ on day one) or carboplatin at a dose to achieve an area under the concentration-time curve (AUC) of $5 \mathrm{mg} / \mathrm{mL}$ on day one, with treatments being repeated every 21 days. Another commonly used regimen was paclitaxel $\left(175 \mathrm{mg} / \mathrm{m}^{2}\right.$ on day one) combined with cisplatin or carboplatin at the same dose as described above. A further neoadjuvant chemotherapy regimen was pemetrexed ( $500 \mathrm{mg} / \mathrm{m}^{2}$ on day one) followed by cisplatin.

Response to the induction treatment was evaluated using CT scans at least two weeks after chemotherapy. The efficacy was classified as complete response (CR), partial response (PR), stable disease (SD) or progressive disease (PD) according to the World Health Organization (WHO) criteria. The presence of lymphadenopathy in the mediastinum (cN2) is defined as lymph nodes greater than $2.0 \mathrm{~cm}$ on the long axis view or $1.0 \mathrm{~cm}$ on the short axis

Table 1 Patient characteristics before treatment

\begin{tabular}{ll}
\hline Characteristic & Value \\
\hline Age, years & 57 \\
\hline median & 38 to74 \\
\hline range & \\
\hline Gender & $69(84 \%)$ \\
\hline male & $13(16 \%)$ \\
\hline Location of the tumor & \\
\hline central & $76(93 \%)$ \\
\hline peripheral & $6(7 \%)$ \\
\hline Biopsy method & $55(67 \%)$ \\
\hline bronchoscopy & $20(24 \%)$ \\
\hline CT-guided needle biopsy & $3(4 \%)$ \\
\hline mediastinoscopy & $4(5 \%)$ \\
\hline EBUS-TBNA & \\
\hline Cell type by biopsy & $47(57 \%)$ \\
\hline squamous & $26(32 \%)$ \\
\hline adenocarcinoma & $9(11 \%)$ \\
\hline non-small-cell & $32(39 \%)$ \\
\hline Clinical stage & $50(61 \%)$ \\
\hline IIB (T3N0M0/T2bN1M0) & \\
\hline IIIA (T1-3N2M0/T3N1M0/T4NO-1M0) & \\
\hline
\end{tabular}


Table 2 Treatment characteristics

\begin{tabular}{ll}
\hline Characteristic & Value \\
\hline Neoadjuvant chemotherapy & \\
\hline platinum & $67(82 \%)$ \\
\hline cisplatin & $15(18 \%)$ \\
\hline carboplatin & \\
\hline second agent & $45(55 \%)$ \\
\hline gemcitabine & $29(35 \%)$ \\
\hline paclitaxel & $8(10 \%)$ \\
\hline pemetrexed & \\
\hline Treatment cycles & $77(94 \%)$ \\
\hline 2 & $3(4 \%)$ \\
\hline 3 & $2(2 \%)$ \\
\hline$>3$ & \\
\hline Type of resection & $16(20 \%)$ \\
\hline pneumonectomy & $52(63 \%)$ \\
\hline lobectomy & $8(10 \%)$ \\
\hline bilobectomy & $2(2 \%)$ \\
\hline wedge resections & $4(5 \%)$ \\
\hline exploration & $29(35 \%)$ \\
\hline Completeness of resection & $2(3 \%)$ \\
\hline R0 & $5(6 \%)$ \\
\hline R1 & \\
\hline R2 & \\
\hline squamous & \\
\hline adenocarcinoma & \\
\hline large cell & \\
\hline
\end{tabular}

Table 3 Complications associated with possible risk factors

\begin{tabular}{lccc}
\hline Variables & \multicolumn{3}{c}{ Complications } \\
\cline { 2 - 4 } & Atelectasis & Arrhythmias & Bronchopleural fistula \\
\hline Laterality & 9 & 5 & 3 \\
\hline right side & 13 & 6 & 0 \\
\hline Left side & 0.859 & 0.831 & 0.073 \\
\hline -value & & & \\
\hline Induction regimen & 11 & 5 & 1 \\
\hline gemcitabine & 10 & 4 & 2 \\
\hline paclitaxel & 0.431 & 0.731 & 0.557 \\
\hline$P$-value & & & 1 \\
\hline Type of resection & $\mathrm{NE}$ & 3 & 2 \\
\hline pneumonectomy & $\mathrm{NE}$ & 6 & 0.513 \\
\hline lobectomy & $\mathrm{NE}$ & 0.387 & \\
\hline$P$-value & & & \\
\hline
\end{tabular}

$\mathrm{NE}^{\mathrm{a}}$ : not evaluable as ipsilateral atelectasis could not occur. view. A thoracotomy was performed after four to six weeks by the same surgical team, on the thoracic unit, after the completion of induction chemotherapy. Systematic mediastinal lymph node dissection, rather than lymph node sampling, consisted of levels 2, 3, 4, 7, 8, 9, 10 and 11 on the right as well as 4, 5, 6, 7, 8, 9, 10, 11 on the left. We also resected lobar nodes (level 12), segmental nodes (level 13) and subsegmental nodes (level 14) for accurate staging. Complete resection (R0) was defined as free resection margins with systematic nodal dissection showing the highest mediastinal node being negative, with no extracapsular nodal extension of the tumor. The final pathological examination and analysis was carried out in the same hospital department, and pathological complete response ( $\mathrm{pCR}$ ) was defined as no viable tumor cells in the specimen, as determined by light microscopy. Any complications after the operation were carefully recorded.

\section{Statistical analysis}

Statistical analysis was performed using patched SPSS 17.0 for Windows software (SPSS Inc., Chicago, IL, USA). Data were tested for significance with the $\chi^{2}$ or Fisher's exact test for discrete variables, and with the $t$-test for continuous variables. OS and DFS were estimated using the Kaplan-Meier method. The impact on survival of variables was assessed using univariate analysis in order to select related clinical variables and the log-rank test and Cox regression analysis to identify the effect of the covariates. Results of analyses were considered significant at a level of $P<0.05$.

\section{Results}

Between 2007 and 2011, 98 patients underwent surgery following neoadjuvant chemotherapy, of which 82 cases were considered for inclusion in this retrospective

Table 4 Clinical response rate and $\mathrm{pCR}$ rate with different regimens

\begin{tabular}{lccccc}
\hline Variables & \multicolumn{5}{c}{ Radiographic response } \\
\cline { 2 - 6 } & CR/PR & SD/PD & RR $^{\text {a }}$ & P-value & pCR \\
\hline All patients $\left(n=82^{\text {b }}\right)$ & 45 & 37 & $55 \%$ & & $5(6 \%)$ \\
\hline gemcitabine & 24 & 21 & $53 \%$ & & $2(4 \%)$ \\
\hline paclitaxel & 18 & 11 & $62 \%$ & 0.309 & $3(10 \%)$ \\
\hline squamous $(\mathrm{n}=51)$ & 29 & 22 & $57 \%$ & & $4(8 \%)$ \\
\hline gemcitabine & 18 & 14 & $56 \%$ & & \\
\hline paclitaxel & 11 & 8 & $58 \%$ & 0.572 & \\
\hline adenocarcinoma $(\mathrm{n}=29)$ & 15 & 14 & $52 \%$ & & $1(3 \%)$ \\
\hline gemcitabine & 6 & 6 & $50 \%$ & & \\
\hline paclitaxel & 6 & 3 & $67 \%$ & & \\
\hline pemetrexed & 3 & 5 & $38 \%$ & 0.517 & \\
\hline
\end{tabular}

${ }^{\mathrm{a} R R}$ : response rate.

${ }^{\mathrm{b}}$ Note: Eight of the 82 patients who received pemetrexed were excluded in the comparison between gemcitabine and paclitaxel because pemetrexed was used only in patients with adenocarcinoma. 


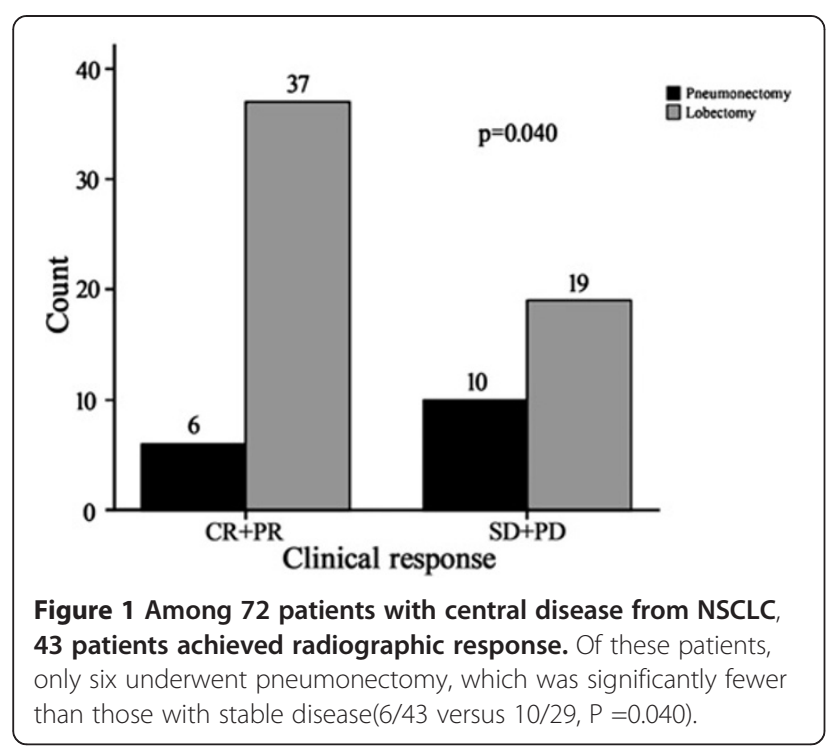

analysis. Of the 16 patients excluded, six were classified as N3 or M1 at diagnosis, six received induction regimens other than cisplatin or carboplatin, and two patients received just one treatment cycle preoperatively; a further two patients were excluded due to having received induction radiotherapy. The clinical characteristics of the selected 82 patients prior to treatment are given in Table 1. In general, this cohort of patients was male with central squamous carcinoma commonly diagnosed by bronchoscopy. Most patients received two cycles of gemcitabine $(55 \%)$ or paclitaxel (35\%), in combination with cisplatin (82\%) or carboplatin (18\%). Resections consisted of 16 pneumonectomies (20\%), 52 lobectomies (63\%), eight bilobectomies (10\%) and two wedge resections (2\%). A thoracotomy and exploration at the time of operation was performed on a further four patients (5\%) due to unresectability or pleural dissemination. Of the patients who received resections, 20 underwent sleeve lobectomy or bronchoplasty, two underwent carinal resection with right pneumonectomy, eight underwent angioplasty
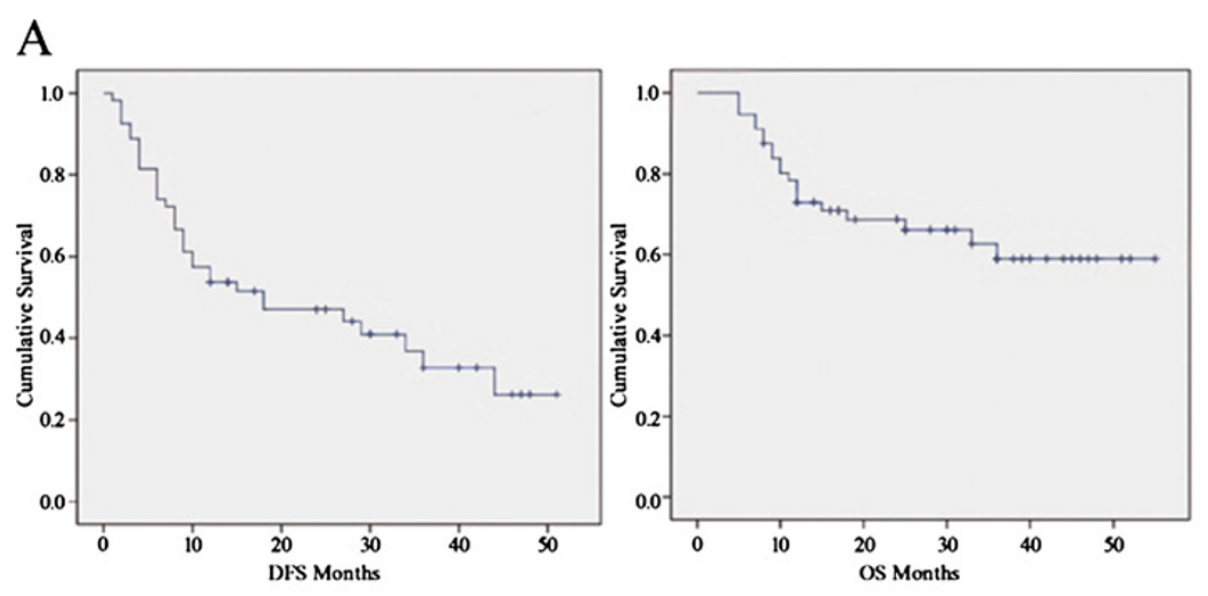

B
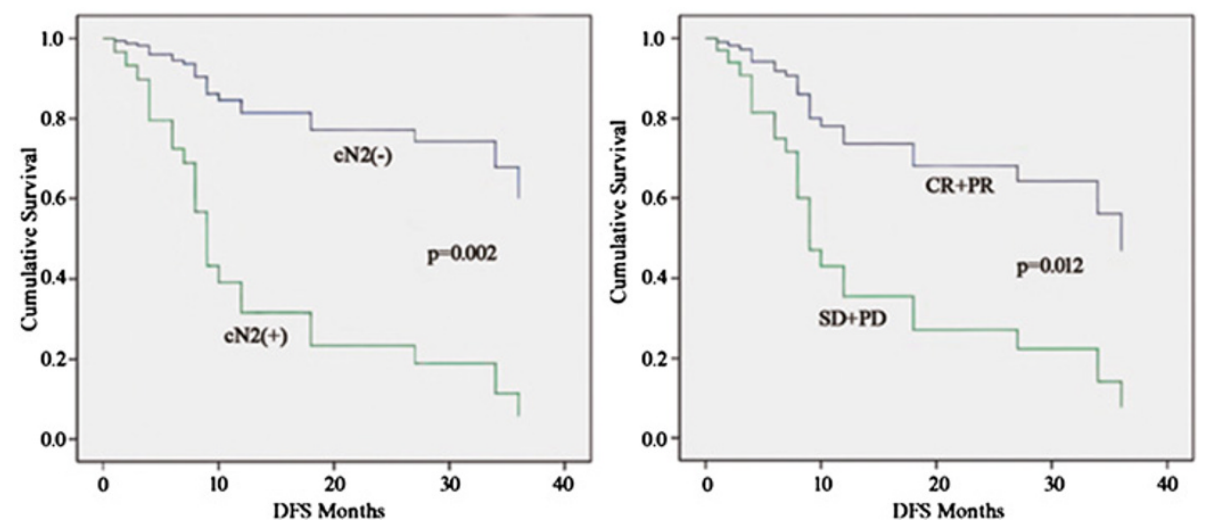

Figure 2 (A) Kaplan-Meier DFS, median DFS time was 18 months (95\% cumulative survival 0.6 to 35.4 months), the DFS rate at one,

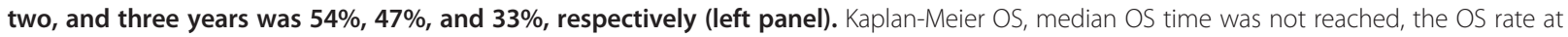
one, two, and three years was 73\%,69\%, and 59\%, respectively (right panel). (B) DFS differences in cN2 (left panel) and clinical response (right panel) after adjustment for other factors. 
of either the pulmonary artery or superior vena cava, and another seven patients underwent broncho-angioplastic (sleeve) lobectomies. R0 resection was documented in 76 patients (93\%); the remaining patients had R1 or R2 resection. The treatment regimens are shown in Table 2.

No patients died intraoperatively but one patient died within 30 days of surgery due to respiratory failure following a bronchovascular sleeve resection: the overall postoperative mortality was $1.2 \%$. Regarding postoperative morbidity, the most common complications were atelectasis (26.8\%) and supraventricular arrhythmias (13.4\%). Bronchopleural fistulas were recorded in three patients: one of whom underwent right pneumonectomy, one underwenta right middle and lower lobectomy, and one had a right lower lobectomy. Other complications included one case each of chylothorax, empyema and pneumonia. There were no hemothoraces requiring reexploration or cases of pulmonary embolism after surgery, and the total postoperative morbidity was $45.1 \%$. An analysis of complications associated with the different neoadjuvant chemotherapy regimens, type of resection, and laterality was performed. No apparent differences in complications were noted between patients who received gemcitabine or paclitaxel combined with platinum, nor was the type of surgery a significant factor. However, a right-sided procedure was associated with an increased trend towards bronchopleural fistula, although the difference was not statistically significant $(P=0.073)$ (data shown in Table 3).

The radiographic response of the primary tumor to induction chemotherapy was evaluated. CR was observed in $11 \%$ of patients $(9 / 82)$, while PR was noted in $44 \%$ of patients (36/82), resulting in an overall response rate of $55 \%$. 37 patients with SD and no PD were assessed. Pathological response was evaluated with five $\mathrm{pCR}$ being confirmed, including four $\mathrm{CR}$ and one PR by clinical evaluation. The pCR rate was $6.1 \%$. The response to treatment with the two major chemotherapy schedules (gemcitabine and paclitaxel) was not significantly different $(P=0.309)$. Subset analyses are summarized in Table 4 and showed no significant

Table 5 Univariate and multivariate predictors of disease-free survival (DFS)

\begin{tabular}{|c|c|c|c|c|}
\hline Variable & Subset & HR & $95 \% \mathrm{Cl}$ & $P$-value \\
\hline \multicolumn{5}{|l|}{ Univariate analysis } \\
\hline \multirow[t]{2}{*}{ age } & $>60$ & & & \\
\hline & $\leq 60$ & 0.845 & 0.425 to 1.680 & 0.632 \\
\hline \multirow[t]{2}{*}{ sex } & male & & & \\
\hline & female & 2.133 & 0.954 to 4.769 & 0.065 \\
\hline \multirow[t]{2}{*}{ histological type } & squamous & & & \\
\hline & nonsquamous & 2.191 & 1.088 to4.409 & 0.028 \\
\hline \multirow[t]{2}{*}{ induction regimen } & gemcitabine & & & \\
\hline & paclitaxel & 0.466 & 0.227 to 0.957 & 0.038 \\
\hline \multirow[t]{2}{*}{ T size before chemotherapy } & $>5 \mathrm{~cm}$ & & & \\
\hline & $\leq 5 \mathrm{~cm}$ & 0.645 & 0.289 to 1.440 & 0.285 \\
\hline \multirow[t]{2}{*}{$\mathrm{cN} 2$} & $(+)$ & & & \\
\hline & $(-)$ & 0.186 & 0.073 to 0.474 & 0.0004 \\
\hline \multirow[t]{2}{*}{ clinical response } & $\mathrm{CR} / \mathrm{PR}$ & & & \\
\hline & $\mathrm{SD} / \mathrm{PD}$ & 0.654 & 0.329 to 1.301 & 0.226 \\
\hline \multirow[t]{2}{*}{ type of resection } & lobectomy & & & \\
\hline & pneumonectomy & 1.403 & 0.576 to3.419 & 0.456 \\
\hline \multirow[t]{2}{*}{ T size after chemotherapy } & $>3 \mathrm{~cm}$ & & & \\
\hline & $\leq 3 \mathrm{~cm}$ & 0.561 & 0.245 to 1.287 & 0.173 \\
\hline \multirow[t]{2}{*}{ pN status } & N2 & & & \\
\hline & No/N1 & 1.249 & 0.833 to 1.873 & 0.283 \\
\hline \multirow[t]{2}{*}{ pN status } & No & & & \\
\hline & N1/N2 & 1.647 & 0.804 to3.373 & 0.172 \\
\hline \multicolumn{5}{|l|}{ Multivariate analysis } \\
\hline \multirow[t]{2}{*}{$\mathrm{cN} 2$} & $(+)$ & & & \\
\hline & $(-)$ & 0.179 & 0.060 to 0.531 & 0.002 \\
\hline \multirow[t]{2}{*}{ clinical response } & $C R / P R$ & & & \\
\hline & $\mathrm{SD} / \mathrm{PD}$ & 0.295 & 0.114 to0.766 & 0.012 \\
\hline
\end{tabular}


difference in response rate using gemcitabine, paclitaxel and pemetrexed for the major histological types (squamous and adenocarcinoma), $(P=0.572,0.517$, respectively). Seventy-two patients were identified with central disease and underwent resection surgery (10 cases were excluded either due to having undergone exploration only or to the presence of peripheral disease). Among these patients, 43 had a radiographic response (PR/CR), while 29 patients had stable disease. There was no significant difference in $\mathrm{T}$ size before chemotherapy between the two groups $(P=0.739)$, although more pneumonectomies were performed in the patients with stable disease $(P=0.04)$ (Figure 1 ).

Among the 82 patients, 54 had a follow-up time of more than 18 months and these were evaluated. The median follow-up time was 38.6 months, with a median DFS time of 18 months (95\% cumulative survival, 0.6 to 35.4 months)and median OS time was not reached during the study's follow-up period (Figure 2A). The DFS rate at one, two, and three years was $54 \%, 47 \%$, and $33 \%$, while the OS rate was $73 \%, 69 \%$, and $59 \%$, respectively. In a univariate analysis, the effects of several factors on DFS were evaluated, including age, sex, histological type, neoadjuvant chemotherapy regimen, radiographic response and radiographic $\mathrm{T}$ size before chemotherapy, lymphadenopathy in the mediastinum before chemotherapy $(\mathrm{cN} 2)$, radiographic $\mathrm{T}$ size after chemotherapy, type of resection, pathological mediastinal lymph node metastasis $(\mathrm{pN} 2)$ and pathological lymph node metastasis (pN1/N2). Three univariate predictors of DFS were identified: histological type, neoadjuvant chemotherapy regimen and mediastinal lymphadenopathy (cN2). Male patients, a clinical response to therapy, T size less than $30 \mathrm{~mm}$ after chemotherapy, and pathological N0, all showed improved DFS times. Univariate predictors with $P$-values of at least 0.25 were entered into a multivariate model. Ultimately, we identified radiographic response $(P=0.012)$, along with $\mathrm{cN} 2(P=0.002)$ as predictors of DFS. The HRs, respective $95 \%$ confidence intervals $(\mathrm{CI})$ and $P$-values are summarized in Table 5 . As shown in Figure 2B, the survival curves demonstrate significant differences between $\mathrm{cN} 2+$ and $\mathrm{cN} 2$ - (left panel) and between $\mathrm{CR}+\mathrm{PR}$ and $\mathrm{SD}+\mathrm{PD}$ (right panel).

\section{Discussion}

Central lung cancer with or without mediastinal lymphadenopathy is a problem that thoracic surgeons continue to face. Direct resection of the tumor is challenging, incurring a high risk of massive hemorrhage and the discovery of intraoperative unresectability. In our retrospective review, $93 \%$ of patients had central disease $(76 / 82)$ of whom $48 \%(39 / 82)$ had, at diagnosis, involvement of central great vessels such as the pulmonary artery, pulmonary vein or superior vena cava. 35\% (29/82) of patients had atelectasis or the possibility of requiring pneumonectomy if resected directly. In a survival analysis, it has been proven that complete resections have a favorable impact on survival compared to incomplete resections [7], even in the case of mediastinal invasion T4 disease [8]. Surgery also offers improved local control rates and OS when compared to radiotherapy following induction therapy $[9,10]$, indicating that $\mathrm{R} 0$ resection remains the cornerstone of treatment

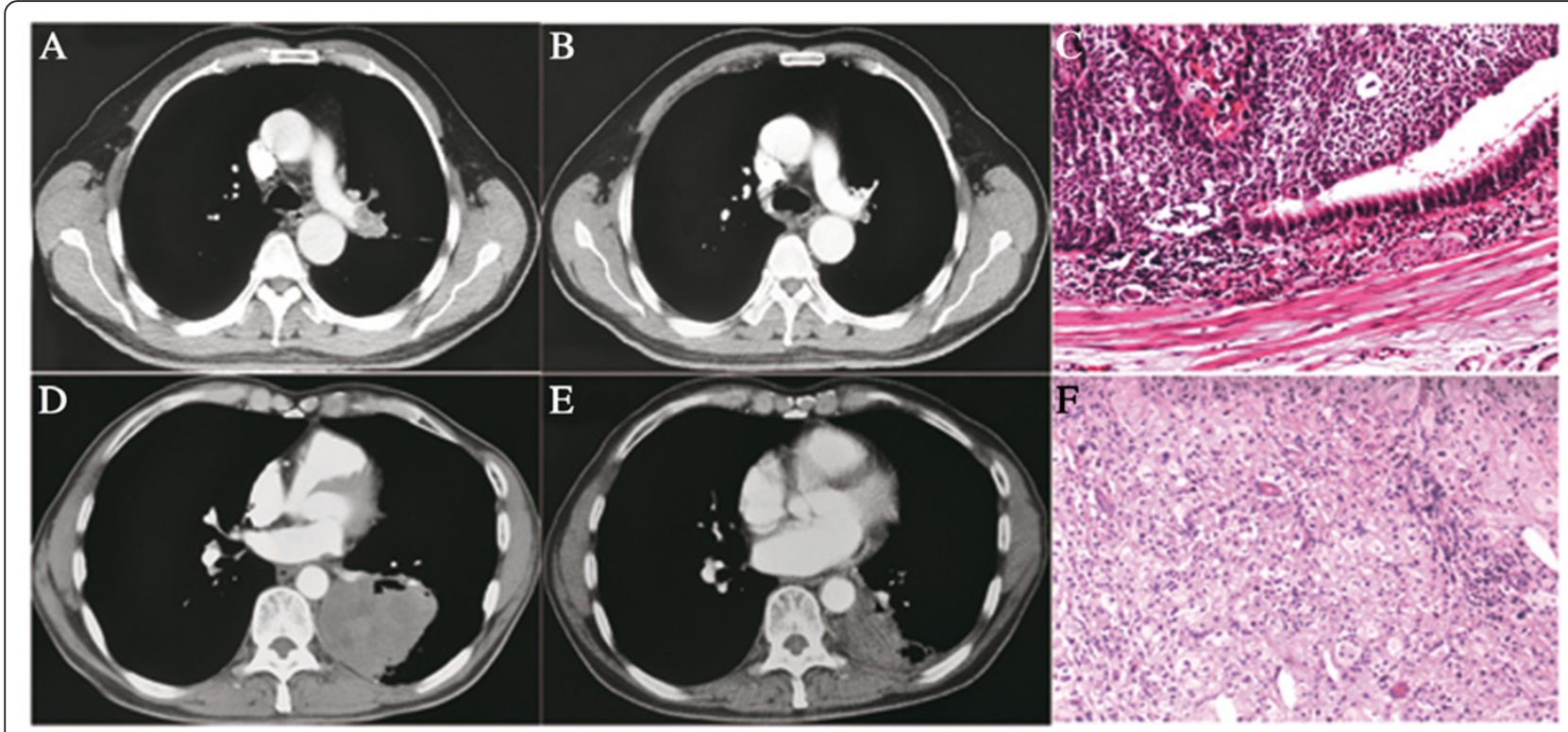

Figure 3 Tumor in the left upper lobe (A) presented a CR after two cycles of induction chemotherapy with gemcitabine plus cisplatin (B), although pathological examination found residual viable tumor by light microscopy (C). Another tumor in left lower lobe (D) achieved a PR after two cycles of paclitaxel plus cisplatin induction therapy $(\mathbf{E})$, while no cancer cells were seen in the residual specimen, and all the tumor was replaced by abundant foamy cells and lymphocytic infiltration (F). 
for NSCLC. The complete resection rate in our study was $93 \%$, which is similar to that found in previous trials (77.4 to $93 \%)[3,7,11,12]$. Although this is a retrospective study and the results would be diminished if the overall intentto-treat (ITT) population were considered, this high R0 resection rate is still promising for cases of locally advanced central disease after chemotherapy. Clearly, patients with the above features present more intraoperative technical challenges to the thoracic surgeon and require more careful postoperative care from surgeons who have considerable experience in handling this patient population [13]. In our study, the $1.2 \%$ overall postoperative mortality is encouraging and lower than that previously reported (3 to 5\%) [3,6,7]. Postoperative complications were acceptable and there were no differences observed between chemotherapy regimens and the types of resection. All three bronchopleural fistula cases occurred in right-sided procedures. This is consistent with previous results where neoadjuvant chemotherapy when followed by a right-sided procedure, especially a pneumonectomy, is an important causal factor of bronchopleural fistula [14]. We conclude that the local intrinsic anatomy may be responsible for the fistula if the procedure included a right lower lobectomy, while induction therapy is another factor that hampers bronchial stump healing.

We observed a comparable response rate of $55 \%$ and a $\mathrm{pCR}$ rate of $6.1 \%$, which are within the ranges of those reported [6,7,15-17]. The pCR rate is considered to be an important predictor of survival in patients receiving induction chemotherapy followed by surgical resection
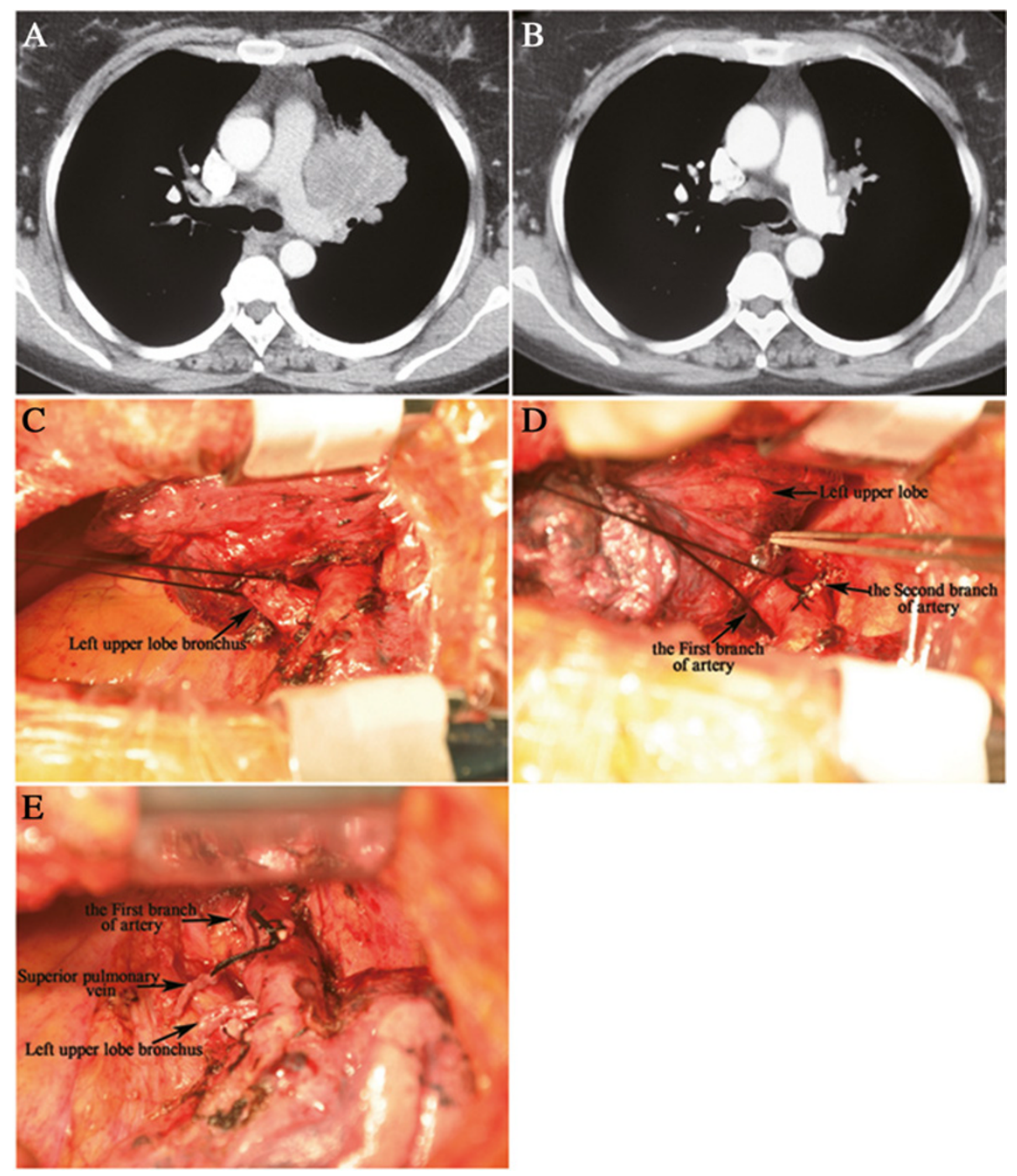

Figure 4 This patient with left upper lobe lung cancer had a high risk of pneumonectomy if resected directly due to involvement of pulmonary artery (A). However, after two cycles of induction chemotherapy, the tumor achieved significant remission (B). During the isolation of the upper lobe bronchus and the first branch of pulmonary artery, no significant invasion was encountered at the proximal portion (C, D). Finally, the procedure of lobectomy was performed without angioplasty or bronchoplasty (E). 
[18]. However, the reliability of radiographic CR to predict $\mathrm{PCR}$ is disappointing, with a high false negative rate of approximately $50 \%$ by CT and $30 \%$ by PET/CT [19]. In our study of nine cases with radiographic $\mathrm{CR}$, only four $(44 \%)$ were confirmed pCR with another one case confirmed from the radiographic PR cohort. This implies that surgical resection cannot be avoided following induction therapy since the rate of complete clearance of tumor using chemotherapy is low and difficult to predict preoperatively (Figure 3). Gemcitabine and paclitaxel were two major regimens used as induction therapy in our study which, in previous studies, had given good response rates for preoperative chemotherapy, ranging from 35 to $70.2 \%[6,17,20]$ and 41 to $56 \%[3,4,20]$, respectively. Our analysis showed similar results with a $53 \%$ response rate with gemcitabine and $62 \%$ with paclitaxel. In addition, we compared these regimens in different histological types, finding no significant difference in response rate. This result is consistent with that reported in The Eastern Cooperative Oncology Group (ECOG) 1594 trial and other retrospective analyses of advanced disease aimed at comparing efficacy by histological type using different regimens [21-23]. This suggests the choice of induction regimen cannot be made by considering tumor histological type alone, and further studies are required to match candidates with the appropriate regimen in order to achieve the expected response rate. Ribonucleotide reductase M1 (RRM1) and thymidylate synthase (TS) mRNA levels were once reported to be predictive of disease response and considered useful parameters for the treatment selection of gemcitabine or pemetrexed. This observation suggested promising potential for further research in this field [24].

Whether and to what extent neoadjuvant chemotherapy could change the type of resection or even enable treatment of unresectable disease remains controversial
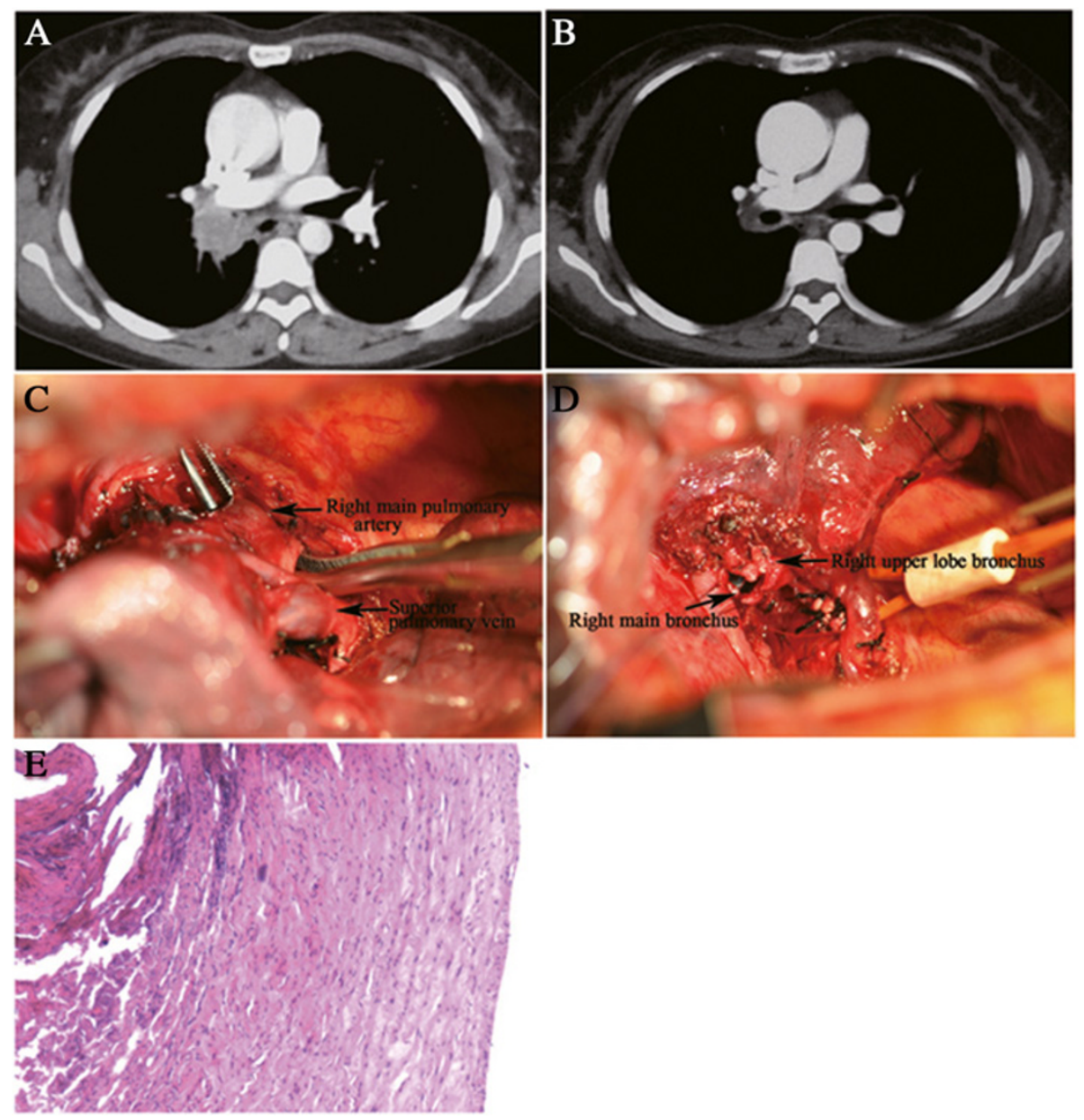

Figure 5 To resect this centrally located tumor is also challenging (A), but two cycles of gemcitabine combined with cisplatin made it possible to preserve lung tissue and avoid pneumonectomy (B). During the resection, the right main pulmonary artery was successfully isolated and controlled (C). Finally, the procedure of right middle and lower lobectomy with bronchoplasty was performed (D), and the arterial margin was found to be free of tumor (E). 
and unclear in most published studies. Disease evaluation is based on radiographic images which are subjective and highly dependent on the experience and expertise of the thoracic surgeon [13], and the type of surgery cannot be determined until an intraoperative exploration is performed. MRC-LU22 once reported that a small proportion of patients (about 5\%) were able to undergo a lobectomy rather than a pneumonectomy as a result of neoadjuvant chemotherapy [2]. In all cases of central disease that had been resected, we observed that the number of successful pneumonectomies was significantly higher in the SD group than in the CR or PR group $(P=0.040)$. Two cases of unresectable disease occurred in the former group, which supports the possible theory that potential pneumonectomies for unresectable disease could be avoided in favor of bronchoplasty or angioplasty procedures by means of efficacious preoperative chemotherapy. Although a clinical trial designed to confirm this function of induction therapy would not be possible, we believe that induction chemotherapy facilitates and simplifies the surgery of patients with central disease as illustrated in Figures 4, 5, and 6. Many studies have reported that pneumonectomy was one of the major factors influencing outcome in patients with locally advanced NSCLC after induction chemotherapy [14,15,25]. Statistically significant differences were observed in postoperative mortality for pneumonectomies (11.3\%) compared with lobectomies $(2.4 \%)$, especially for right pneumonectomies [26]. Furthermore, a low compliance rate in accepting postoperative adjuvant chemotherapy was observed in patients who underwent a pneumonectomy [27]. Therefore, in our center, given the considerable abnormalities in the respiratory and cardiovascular systems in our patients,
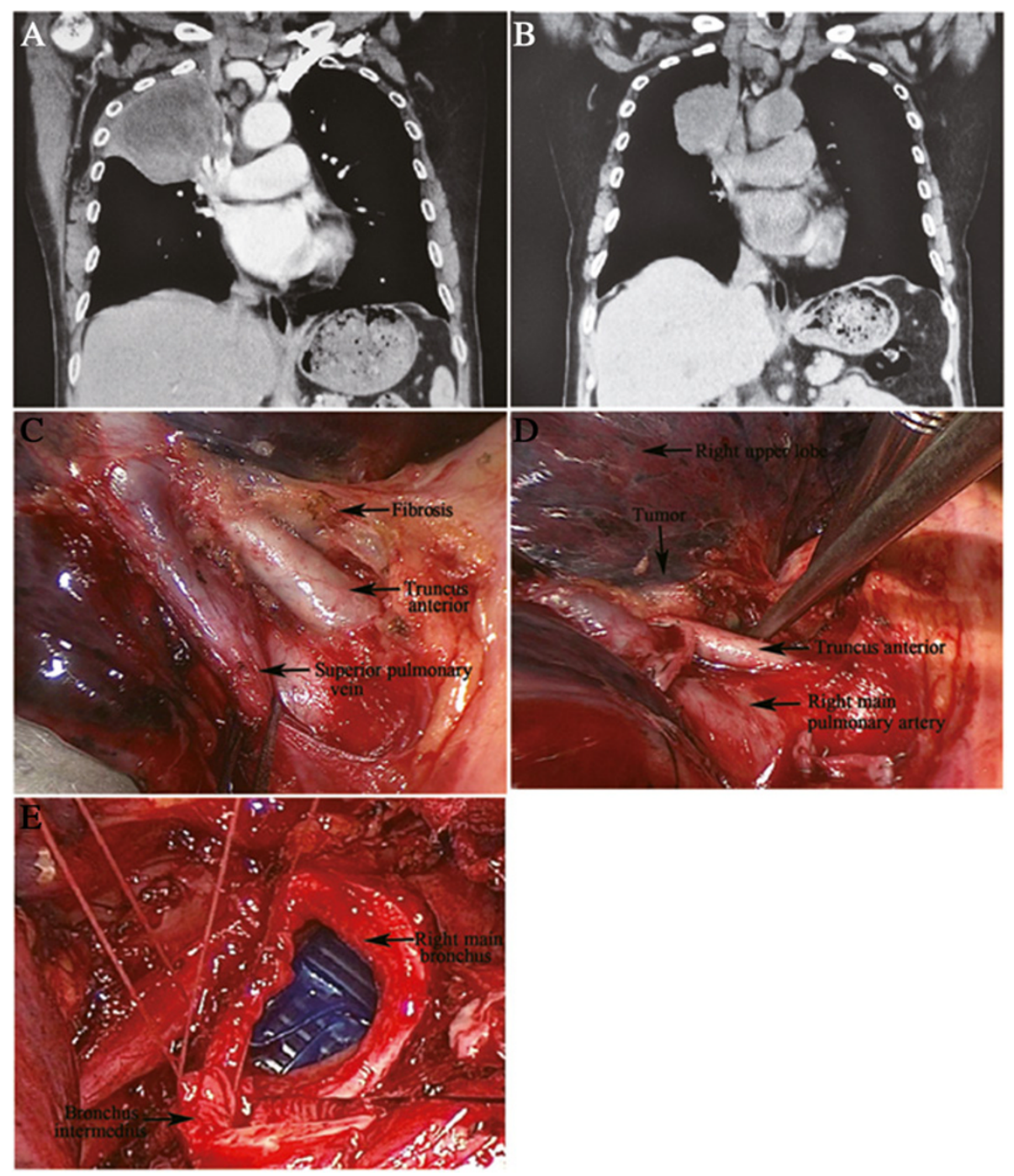

Figure 6 The upper right pleural cavity was occupied by a large squamous carcinoma, and the right hilum had also been invaded (A). After neoadjuvant chemotherapy, the tumor shrank significantly (B). Although the induction therapy created fibrosis in the hilum (C), the truncus anterior was exposed and isolated successfully (D). Finally, the patient underwent right upper lobe sleeve resection without angioplasty (E). 
those patients who had had a pneumonectomy did not receive adjuvant chemotherapy or radiotherapy due to the potential toxicity risk of these treatments. Despite this, neither excess morbidity nor shortened DFS were found in this cohort; findings which we attributed to good postoperative care, reasonable patient selection and appropriate induction chemotherapy.

The OS rates of $73 \%$ at one year and $59 \%$ at three years were within the range of those reported by previous studies which included all the pathological stages $[3,6,12]$. These represent the reality of clinical practice in our center. Because the median OS time was not reached in our study, we focused on DFS time which is closely linked to surgery and perioperative therapy. In previous retrospective studies, it has been demonstrated that age, complete resection, pneumonectomy and pathological stage all had a significant impact on survival $[7,15,16,25]$. In addition to these factors, mediastinal downstaging is another important determinant of survival, particularly for stage IIIA disease [16,28]. During our study, downstaging was not considered due to the unreliable evaluation of clinical nodal $(\mathrm{cN})$ status by $\mathrm{CT}$. We noted a trend toward difference in DFS for pathological nodal $(\mathrm{pN})$ status, although this was not statistically significant $(P=0.172)$. However, we observed that patients displaying central disease with mediastinal lymphadenopathy had a high postoperative risk of recurrence unless a pNO status was achieved with induction chemotherapy.

\section{Conclusion}

This is a retrospective review of a group of patients characterized by having central disease from clinical stage IIB-IIIA non-small-cell lung cancer and who had received two cycles of platinum-based chemotherapy prior to surgical resection. Although the study was potentially limited due to the small number of patients, short follow-up period and unreliable $\mathrm{N}$ staging before chemotherapy, we achieved a comparable response rate and $\mathrm{pCR}$ rate with a high $\mathrm{R} 0$ resection and low mortality rate, demonstrating the feasibility and efficacy of this relatively simple but standard treatment model. The good clinical response might have had some influence on avoiding pneumonectomy and unresectability. Additionally, we found that radiographically stable disease, together with cN2, was considered an adverse factor for DFS.

\section{Consent}

Written informed consent was obtained from the patient for publication of this report and any accompanying images.

\footnotetext{
Abbreviations

AUC: Area under the concentration-time curve; CR: Complete response; CT: Computed tomography; DFS: Disease-free survival; ITT: Intent-to-treat; NSCLC: Non-small-cell lung cancer; OS: Overall survival; pCR: Pathological
}

complete response; PD: Progressive disease; PET/CT: Positron emission tomography - computed tomography; PR: Partial response; RRM1: Ribonucleotide reductase M1; SD: Stable disease; TS: Thymidylate synthase.

\section{Competing interests}

The authors declare that they have no competing interests.

\section{Authors' contribution}

SY, QFZ, YS, JF and CL participated in the design of the study, performed the statistical analysis and drafted the manuscript. YYM and NW participated in study design, literature search and coordination. SY, QFZ, YS and JF participated in the analysis of experimental results. YY conceived of the study, participated in its design and coordination, and helped to draft the manuscript. All authors read and approved the final manuscript.

\section{Acknowledgments}

We are grateful to Yuzhao Wang, Jia Wang, Yuan Feng and Yuquan Pei at the department of Thoracic Surgery II, Peking University Cancer Hospital \&lnstitute, for their assistance with sample collecting.

\section{Author details}

'Department of Thoracic Surgery II, Key Laboratory of Carcinogenesis and Translational Research (Ministry of Education), Peking University Cancer Hospital \& Institute, Peking, China. ${ }^{2}$ Department of Pathology, Key Laboratory of Carcinogenesis and Translational Research (Ministry of Education), Peking University Cancer Hospital \& Institute, Peking, China. ${ }^{3}$ Department of Thoracic Medical Oncology II, Key Laboratory of Carcinogenesis and Translational Research(Ministry of Education), Peking University Cancer Hospital \& Institute, Peking, China

Received: 23 October 2012 Accepted: 23 February 2013

Published: 21 March 2013

\section{References}

1. Goldstraw P, Crowley J, Chansky K, Giroux DJ, Groome PA, Rami-Porta R, Postmus PE, Rusch V, Sobin L: The IASLC Lung Cancer Staging Project: proposals for the revision of the TNM stage groupings in the forthcoming (seventh) edition of the TNM classification of malignant tumors. J Thorac Oncol 2007, 2:706-714.

2. Gilligan D, Nicolson M, Smith I, Groen H, Dalesio O, Goldstraw P, Hatton M, Hopwood P, Manegold C, Schramel F, et al: Preoperative chemotherapy in patients with resectable non-small-cell lung cancer: results of the MRC LU22/NVALT 2/EORTC 08012 multicentre randomized trial and update of systematic review. Lancet 2007, 369:1929-1937.

3. Pisters KM, Vallieres E, Crowley JJ, Franklin WA, Bunn PA Jr, Ginsberg RJ, Putnam JB Jr, Chansky K, Gandara D: Surgery with or without preoperative paclitaxel and carboplatin in early-stage non-small-cell lung cancer: Southwest Oncology Group Trial S9900, an intergroup, randomized, phase III trial. J Clin Oncol 2010, 28:1843-1849.

4. Felip E, Rosell R, Maestre JA, Rodriguez-Paniagua JM, Moran T, Astudillo J, Alonso G, Borro JM, Gonzalez-Larriba JL, Torres A, et al: Preoperative chemotherapy plus surgery versus surgery plus adjuvant chemotherapy versus surgery alone in early-stage non-small-cell lung cancer. J Clin Oncol 2010, 28:3138-3145.

5. Song WA, Zhou NK, Wang W, Chu XY, Liang CY, Tian XD, Guo JT, Liu X, Liu $Y$, Dai WM: Survival benefit of neoadjuvant chemotherapy in non-small -cell lung cancer: an updated meta-analysis of 13 randomized control trials. J Thorac Oncol 2010, 5:510-516.

6. Scagliotti GV, Pastorino U, Vansteenkiste JF, Spaggiari L, Facciolo F, Orlowski TM, Maiorino L, Hetzel M, Leschinger M, Visseren-Grul C, Torri V: Randomized phase III study of surgery alone or surgery plus preoperative cisplatin and gemcitabine in stages IB to IIIA non-small-cell lung cancer. J Clin Oncol 2012, 30:172-178.

7. Martin J, Ginsberg RJ, Venkatraman ES, Bains MS, Downey RJ, Korst RJ, Kris $M G$, Rusch WW: Long-term results of combined-modality therapy in resectable non-small-cell lung cancer. J Clin Oncol 2002, 20:1989-1995.

8. Yang $H X$, Hou X, Lin P, Rong TH, Yang H, Fu JH: Survival and risk factors of surgically treated mediastinal invasion T4 non-small-cell lung cancer. Ann Thorac Surg 2009, 88:372-378.

9. van Meerbeeck JP, Kramer GW, Van Schil PE, Legrand C, Smit EF, Schramel F, Tjan-Heijnen VC, Biesma B, Debruyne C, van Zandwijk N, et al: 
Randomized controlled trial of resection versus radiotherapy after induction chemotherapy in stage IIIA-N2 non-small-cell lung cancer. J Natl Cancer Inst 2007, 99:442-450.

10. Albain KS, Swann RS, Rusch WW, Turrisi AT 3rd, Shepherd FA, Smith C, Chen Y, Livingston RB, Feins RH, Gandara DR, et al: Radiotherapy plus chemotherapy with or without surgical resection for stage III non-small -cell lung cancer: a phase III randomized controlled trial. Lancet 2009, 374:379-386.

11. Aydiner A, Kiyik M, Cikrikcioglu S, Kosar F, Gurses A, Turna A, Yazar A, Dilege S, Goksel T, Cakan A: Gemcitabine and cisplatin as neo-adjuvant chemotherapy for non-small-cell lung cancer: a phase II study. Lung Cancer 2007, 58:246-252.

12. Depierre A, Milleron B, Moro-Sibilot D, Chevret S, Quoix E, Lebeau B, Braun $D$, Breton JL, Lemarie E, Gouva S, et al: Preoperative chemotherapy followed by surgery compared with primary surgery in resectable stage I (except T1N0), II, and IIla non-small-cell lung cancer. J Clin Oncol 2002, 20:247-253.

13. Robinson LA, Ruckdeschel JC, Wagner H Jr, Stevens CW: Treatment of nonsmall-cell lung cancer-stage IIIA: ACCP evidence-based clinical practice guidelines (Second edition). Chest 2007, 132:243S-265S.

14. D'Amato TA, Ashrafi AS, Schuchert MJ, Alshehab DS, Seely AJ, Shamji FM, Maziak DE, Sundaresan SR, Ferson PF, Luketich JD, Landreneau RJ: Risk of pneumonectomy after induction therapy for locally advanced non-small -cell lung cancer. Ann Thorac Surg 2009, 88:1079-1085.

15. Kim AW, Liptay MJ, Bonomi P, Warren WH, Basu S, Farlow EC, Faber LP: Neoadjuvant chemoradiation for clinically advanced non-small-cell lung cancer: an analysis of 233 patients. Ann Thorac Surg 2011, 92:233-241. Discussion 241-233.

16. Paul S, Mirza F, Port JL, Lee PC, Stiles BM, Kansler AL, Altorki NK: Survival of patients with clinical stage IIIA non-small-cell lung cancer after induction therapy: age, mediastinal downstaging, and extent of pulmonary resection as independent predictors. J Thorac Cardiovasc Surg 2011, 141:48-58.

17. Van Zandwijk N, Smit EF, Kramer GW, Schramel F, Gans S, Festen J, Termeer A, Schlosser NJ, Debruyne C, Curran D, Giaccone G: Gemcitabine and cisplatin as induction regimen for patients with biopsy-proven stage IIIA N2 non-small-cell lung cancer: a phase II study of the European Organization for Research and Treatment of Cancer Lung Cancer Cooperative Group (EORTC 08955). J Clin Oncol 2000, 18:2658-2664.

18. Pisters KM, Kris MG, Gralla RJ, Zaman MB, Heelan RT, Martini N: Pathologic complete response in advanced non-small-cell lung cancer following preoperative chemotherapy: implications for the design of future nonsmall-cell lung cancer combined modality trials. J Clin Oncol 1993, 11:1757-1762.

19. de Cabanyes CS, Detterbeck FC: A systematic review of restaging after induction therapy for stage Illa lung cancer: prediction of pathologic stage. J Thorac Oncol 2010, 5:389-398.

20. Pisters KM, Ginsberg RJ, Giroux DJ, Putnam JB Jr, Kris MG, Johnson DH, Roberts JR, Mault J, Crowley JJ, Bunn PA Jr: Induction chemotherapy before surgery for early-stage lung cancer: a novel approach. Bimodality Lung Oncology Team. J Thorac Cardiovasc Surg 2000, 119:429-439.

21. Scagliotti GV, De Marinis F, Rinaldi M, Crino L, Gridelli C, Ricci S, Zhao YD, Liepa AM, Peterson P, Tonato M: The role of histology with common firstline regimens for advanced non-small-cell lung cancer: a brief report of the retrospective analysis of a three-arm randomized trial. J Thorac Oncol 2009, 4:1568-1571.

22. Schiller JH, Harrington D, Belani CP, Langer C, Sandler A, Krook J, Zhu J, Johnson DH: Comparison of four chemotherapy regimens for advanced non-small-cell lung cancer. N Engl J Med 2002, 346:92-98.

23. Treat J, Edelman MJ, Belani CP, Socinski MA, Monberg MJ, Chen R, Obasaju CK: A retrospective analysis of outcomes across histological subgroups in a three-arm phase III trial of gemcitabine in combination with carboplatin or paclitaxel versus paclitaxel plus carboplatin for advanced non-small-cell lung cancer. Lung Cancer 2010, 70:340-346.

24. Bepler G, Sommers KE, Cantor A, Li X, Sharma A, Williams C, Chiappori A, Haura E, Antonia S, Tanvetyanon T, et al: Clinical efficacy and predictive molecular markers of neoadjuvant gemcitabine and pemetrexed in resectable non-small-cell lung cancer. J Thorac Oncol 2008, 3:1112-1118.

25. Kappers I, van Sandick JW, Burgers SA, Belderbos JS, van Zandwijk N, Klomp HM: Surgery after induction chemotherapy in stage IIIA-N2 non-small -cell lung cancer: why pneumonectomy should be avoided. Lung Cancer 2010, 68:222-227.
26. Martin J, Ginsberg RJ, Abolhoda A, Bains MS, Downey RJ, Korst RJ, Weigel $T L$, Kris MG, Venkatraman ES, Rusch WW: Morbidity and mortality after neoadjuvant therapy for lung cancer: the risks of right pneumonectomy. Ann Thorac Surg 2001, 72:1149-1154.

27. Alam N, Shepherd FA, Winton T, Graham B, Johnson D, Livingston R, Rigas J, Whitehead M, Ding K, Seymour L: Compliance with post-operative adjuvant chemotherapy in non-small-cell lung cancer. an analysis of National Cancer Institute of Canada and intergroup trial JBR.10 and a review of the literature. Lung Cancer 2005, 47:385-394.

28. Takeda S, Maeda H, Okada T, Yamaguchi T, Nakagawa M, Yokota S, Sawabata N, Ohta M: Results of pulmonary resection following neoadjuvant therapy for locally advanced (IIIA-IIIB) lung cancer. Eur J Cardiothorac Surg 2006, 30:184-189.

doi:10.1186/1477-7819-11-76

Cite this article as: Lv et al:: A retrospective study: platinum-based induction chemotherapy combined with gemcitabine or paclitaxel for stage IIB-IIIA central non-small-cell lung cancer. World Journal of Surgical Oncology 2013 11:76.

\section{Submit your next manuscript to BioMed Central and take full advantage of:}

- Convenient online submission

- Thorough peer review

- No space constraints or color figure charges

- Immediate publication on acceptance

- Inclusion in PubMed, CAS, Scopus and Google Scholar

- Research which is freely available for redistribution

Submit your manuscript at www.biomedcentral.com/submit
C Biomed Central 